\title{
Small intestinal biopsy in childhood coeliac disease
}

\author{
R. A. RISDON* \\ M.D., M.R.C.Path. \\ E. A. Meinhard $\dagger$ \\ M.B., M.R.C.Path. \\ D. G. WADBROOK $\dagger$ \\ B.Sc. \\ J. W. KEELING*‡ \\ M.B., M.R.C.Path. \\ *The Hospital for Sick Children, Great Ormond Street, and †The Royal Free Hospital, London
}

\begin{abstract}
Summary
Small intestinal biopsies from children with treated and untreated coeliac disease have been analysed morphometrically and compared with controls. Two methods have been used; one, described by Dunnill and Whitehead (1972) provides indices of surface-tovolume ratio and of mucosal volume. The other, described by Meinhard, Wadbrook and Risdon (1965), involves tracing the microscopic image of the biopsy on to computer data cards to produce measured encoded data for direct analysis with a computer.

Biopsies from untreated coeliacs were clearly distinguished from control specimens by both techniques. Comparison of these two groups by computer card morphometry shows the mucosal lesion in coeliac disease to be associated with a spatial redistribution of the tissue components rather than a change in their absolute amounts. No difference in the total mucosal volume was found so that a true mucosal atrophy does not occur in this condition.
\end{abstract}

Surface-to-volume $(c:$ lh) ratios were measured in twenty-eight children treated empirically with a gluten-free diet for suspected coeliac disease, in biopsies taken before and after a gluten challenge. By this means the diagnosis of coeliac disease was confirmed in eighteen of these patients.

In morphologically normal biopsies correlation of $c:$ lh ratios with age showed significantly smaller values in younger children. Slight changes in biopsies from young children should, therefore, be interpreted cautiously and should not necessarily be regarded as pathological on the evidence of the villous pattern alone.

\section{Introduction}

Improvements in biopsy techniques have led to their increased use both for diagnosis and in following a disease process or its response to treatment in serial biopsies from the same individual. This is particularly true of childhood coeliac disease; current definitions of this condition require the demonstration of both a mucosal lesion and its response to

$\ddagger$ Present address: John Radcliffe Hospital, Oxford.

Correspondence: Dr R. A. Risdon, Department of Histopathology, The Hospital for Sick Children, Great Ormond Street, London WC1N 3JH. gluten withdrawal or reintroduction in sequentiad jejunal biopsies (Townley and Barnes, 1973; Andere son, Gracey and Burke, 1972). Increasingly, there iș a need for quantitative methods for assessing the changes seen in these specimens objectively.

Previous attempts to measure jejunal biops㝏 changes have been recently reviewed by Dunnill and Whitehead (1972) and by Chapman et al. (1973). Ir the present study morphometric methods have beem applied to both single and serial biopsies from children. The technique of Dunnill and Whitehead combines point counting and linear intercep principles (Chalkley, Cornfield and Park, 1949) to measure surface-to-volume ratios and mucosar volume indices.

Computer card morphometry (Meinhard, 19.4\% requires the tracing of the microscopic image of fhe $^{\circ}$ biopsy on computer data cards. These are printe $\$$ with a grid, the cross-points of which form matrix of 840 points. Quantitative data are recorded as marks where tissue components overlie the crosso points, thus retaining their spatial arrangement with in the tissue. The data are fed, via an Optical Marle Data Card Reader, into a minicomputer for analysis?

\section{Materials and methods}

Peroral biopsies of small intestinal mucosa were obtained under fluoroscopic control using a Crosby. capsule. The specimens were taken immediately distal to the ligament of Treitz. The handling and processing of the biopsies have been described in detail elsewhere (Risdon and Keeling, 1974).

\section{Morphometry}

Method 1 (Dunnill and Whitehead, 1972)

This technique involves superimposing a patter of fifteen lines of equal length (drawn to the specir fication of Weibel, 1963) on to the image of the biopsy (Fig. 1), using an eye-piece graticule $e_{\sigma}^{\omega}$ Two parameters are counted; 'hits' where the end points of the lines lie over the mucosa, an\& 'cuts' where the lines cross the surface epitheliums The magnification is kept constant, and when counts in each microscopic field are completed the section is racked to the next adjoining field. Counting is continued until a total of about 200 'hits' have bee 


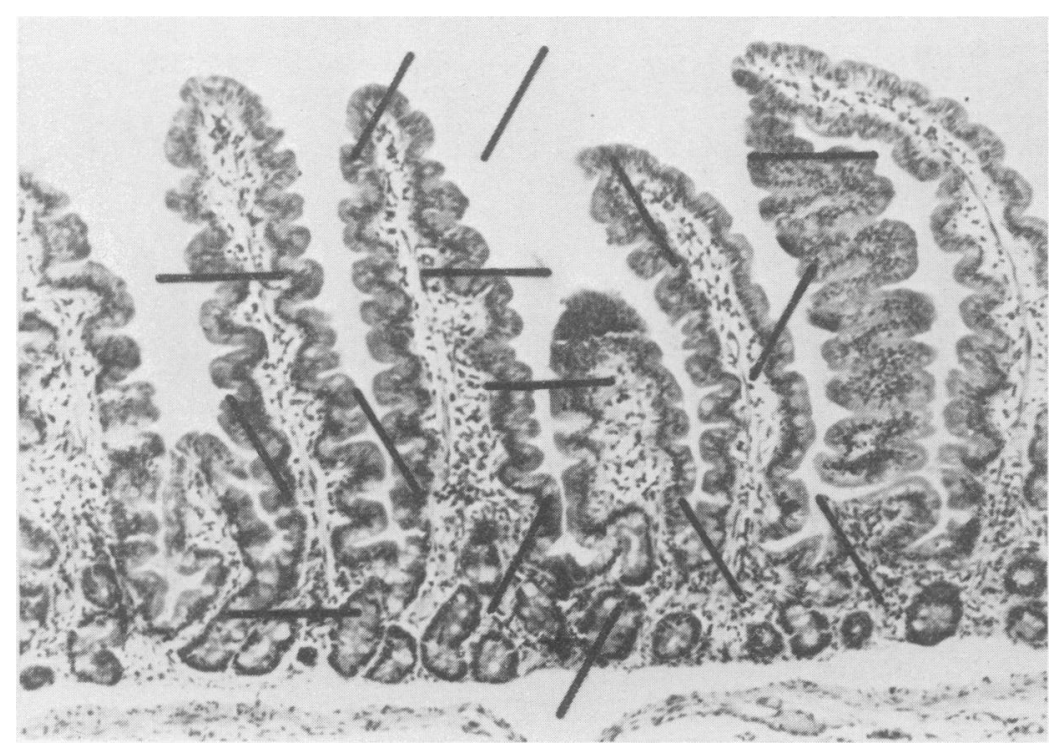

FIG. 1. Superimposed over a section of a control biopsy is a template of fifteen lines of equal length arranged as specified by Weibel (1963). 'Hits' are counted where the endpoints of the lines lie over the mucosa; 'cuts' are counted where the lines cross the surface epithelium. At the magnification used, the length (1) of each line was $1.4 \times 10^{-2} \mathrm{~cm}(\mathrm{HE} \times 17 \cdot 5)$.

recorded. The number of microscopic fields used is also noted. The surface-to-volume ratio index is given by $c:$ lh ( $c$ is the number of 'cuts', $h$ is the number of 'hits' and 1 the length of the lines). The mucosal volume index is given by $\bar{h}$, the average number of 'hits' per microscopic field counted.

From ninety children, 113 jejunal biopsies were studied by this method. Thirty-seven biopsies were obtained from children investigated for short stature or failure to thrive. Since none had investigational evidence of malabsorption and all biopsies were subjectively normal, these specimens were used as 'controls'. Thirty biopsies were taken from children with typical coeliac disease before any dietary treatment. Forty-six were paired biopsies from twenty-three children treated empirically for at least 2 years with gluten-free diet for suspected coeliac disease. This has been diagnosed previously on clinical grounds alone. One biopsy was taken before, and a second biopsy was taken some 12 weeks after reintroduction of dietary gluten.

\section{Method 2 (Meinhard et al., 1975)}

The method requires the tracing of a correctly orientated microscopic image of the biopsy on to computer data cards; the grids printed on the cards provide a point counting graticule of 840 sampling points.

Each drawing is done on two superimposed data cards; an upper punched master card forms a template over a lower component card. Each crosspoint of the grid printed on the component card is visible through a punched hole in the master card. After calibration, selected components of the biopsy are traced on the cards using a drawing tube attachment to the microscope. This produces a sketch on the upper master card and a series of marks on the lower component card (Fig. 2). A different component card is used for each component to be measured but the master card is retained. Thus a composite image of the biopsy is gradually built up on the master card. The component cards are read by an optical mark data card reader. The information is then fed via a 12-line input into a mini-computer in binary image form (i.e. as an array of 1's and 0's). FORTRAN IV programs allow calculation of surface area and component volumes in absolute (metric) units. Calibration before making the drawings means that the distance between lines on the grid is defined and hence an area can be assigned to each sampling point, and by summation to each component within the matrix. Distances between sampling points, diagonally as well as vertically and horizontally, can be measured and thus the distance along a contour can be derived. Similarly, the length of the muscularis mucosae can be measured and the point count and upper contour values can be expressed as an area or perimeter measurement per $1 \mathrm{~mm}$ of muscularis 


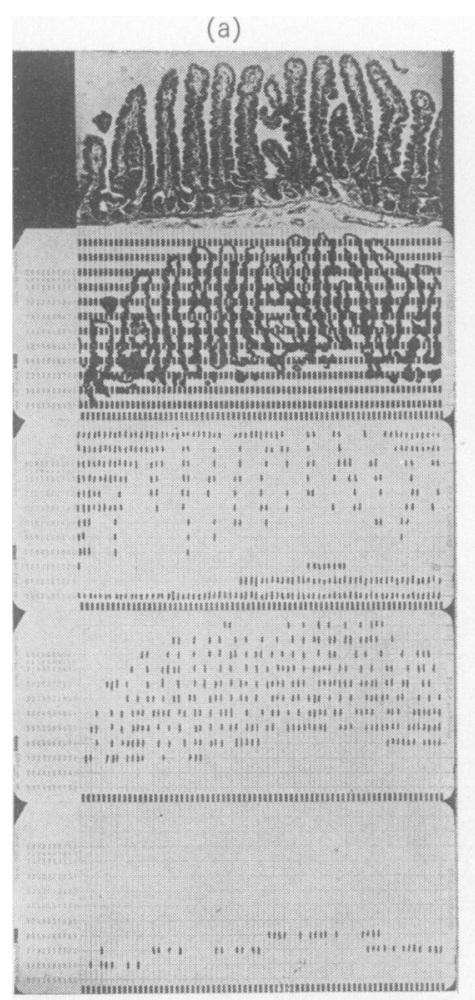

Photomicrograph of the biopsy

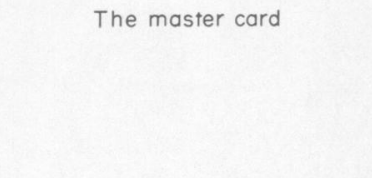

'Not mucosa' component card

Surface epithelium component card

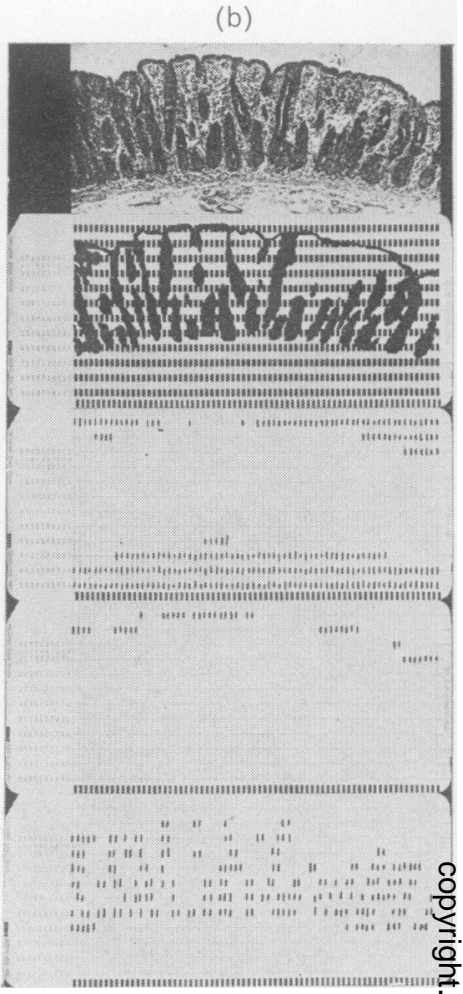

FIG. 2. (a) The progression from a control specimen via the master card to the component cards. (i) Photomicrograph of the biopsy; (ii) the master card; (iii) 'not mucosa' component card; (iv) surface epithelium component card; (v) crypt epithelium component. (b) Similar progression for a 'flat' biopsy from a patient with coeliac disease.

TABLE 1. Surface-to-volume ratios and mucosal volume indices in biopsies from controls and untreated coeliacs

\begin{tabular}{|c|c|c|c|c|c|c|c|}
\hline & \multirow[b]{2}{*}{ No. } & \multicolumn{3}{|c|}{ c : lh ratio } & \multicolumn{3}{|c|}{$\overline{\mathrm{h}}$} \\
\hline & & Range & Mean & s.d. & Range & Mean & s.d. \\
\hline Controls & 37 & $26 \cdot 3-56 \cdot 0$ & $43 \cdot 5$ & $8 \cdot 1$ & $14 \cdot 3-23 \cdot 7$ & $18 \cdot 7$ & $2 \cdot 2$ \\
\hline $\begin{array}{r}\text { Untreated } \\
\text { coeliacs }\end{array}$ & 30 & $4 \cdot 7-14 \cdot 3$ & $9 \cdot 7$ & $2 \cdot 4$ & $14 \cdot 8-23 \cdot 3$ & $19 \cdot 6$ & $2 \cdot 3$ \\
\hline
\end{tabular}

mucosae. Volume proportions and surface-tovolume ratios can also be derived relative to the total mucosal volume.

In this paper some of the results obtained with this method in biopsies from the controls and in twenty-six of the specimens from untreated coeliacs are considered. A fuller and more extended study is reported elsewhere (Meinhard et al., 1975; Wadbrook and Meinhard, 1975).

\section{Results}

\section{Method 1}

Results for the biopsies from controls and untreated coeliacs are set out in Table 1 and Fig. 3.
The numerical values for $c:$ lh ratios and $\overline{\mathrm{h}}$ 옹 indices are different from those previously reported $\rightarrow$ (Risdon and Keeling, 1974), because of changes in methodology. Previously, 'hits' were scored only N when the ends of lines fell on the lamina propria or mucosal glands, thus excluding surface epithelium 0 from volume determinations. Experience with com- $\omega$ puter card morphometry has shown that in normal specimens surface epithelium comprises some $30 \%$ of the total mucosal volume. Differences we previously reported in mucosal volume between con-: trols and 'flat' biopsies have been shown to be $\frac{0}{\circ}$ spurious, and are due to the exclusion of surface $\frac{}{\mathbb{D}}$ epithelium when counting 'hits'. 

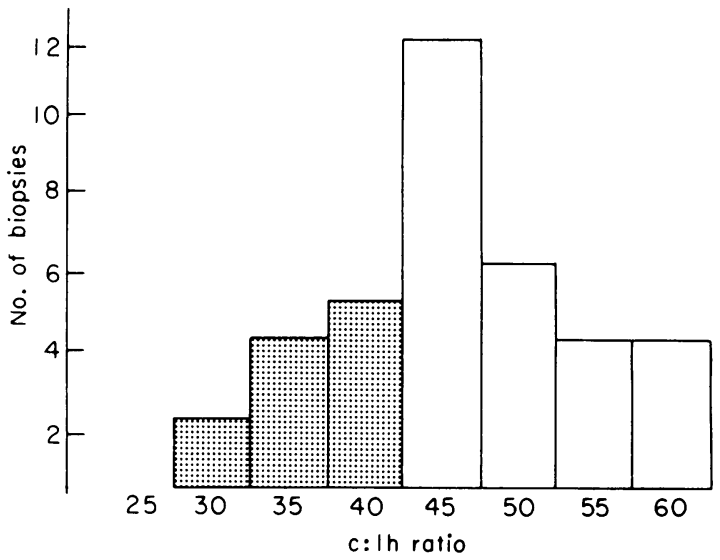

FIG. 3. A histogram showing the normal distribution of $c:$ lh ratios in the thrity-seven control biopsies. The mean age of the 11 cases with $c:$ lh ratios below 40 (corresponding to the shaded area) was $29 \cdot 2$ months, whilst that of the remaining twenty-six cases was $69 \cdot 3$ months. The difference is significant $(t=2 \cdot 78$, $P<0.01$ )
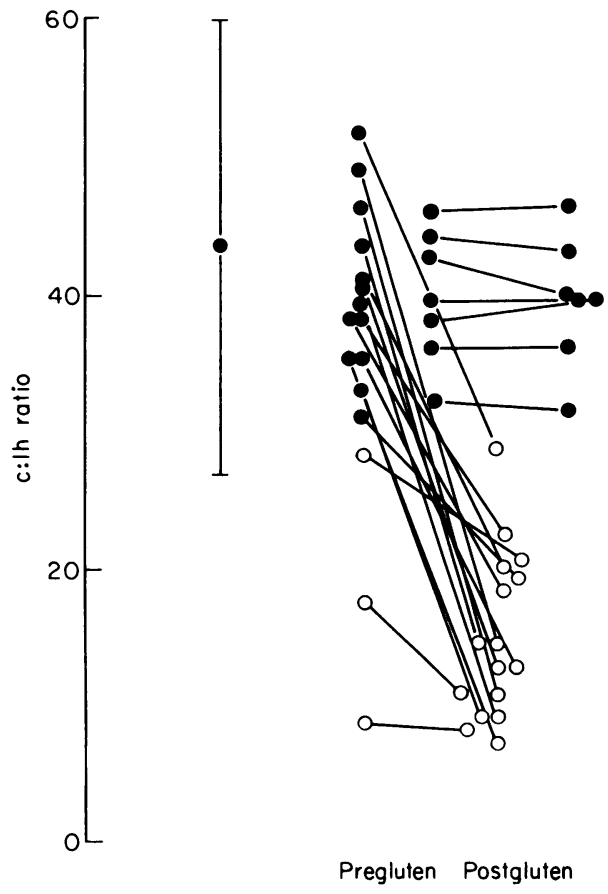

FIG. 4. The $\mathrm{c}: \mathrm{lh}$ ratios in paired biopsies from patients before and after the reintroduction of dietary gluten. The closed circles represent morphologically normal biopsies and the open circles abnormal biopsies. Biopsies from the same patients are joined by lines. Means and twice the standard deviations for controls and biopsies from untreated coeliacs are indicated.

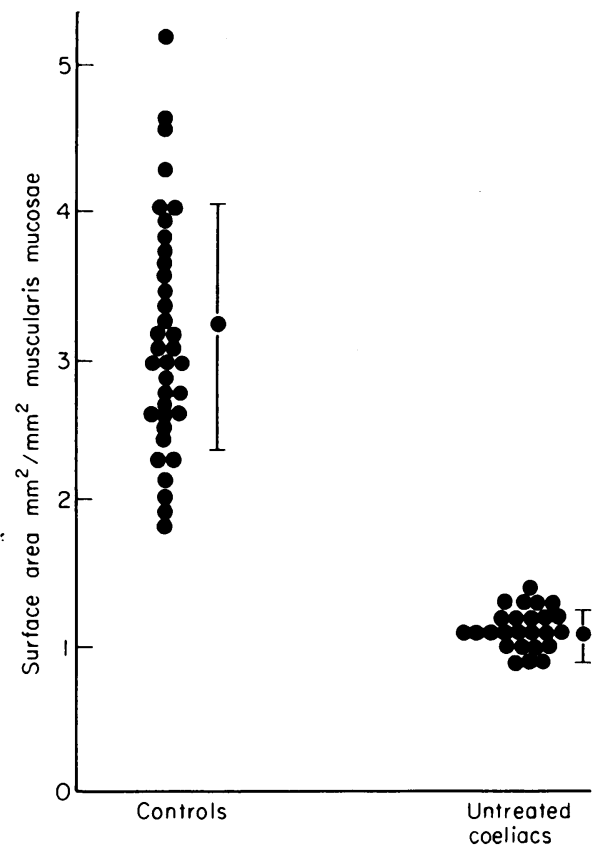

FIG. 5. The surface areas of controls and biopsies from untreated coeliacs. Means and standard deviations are indicated.

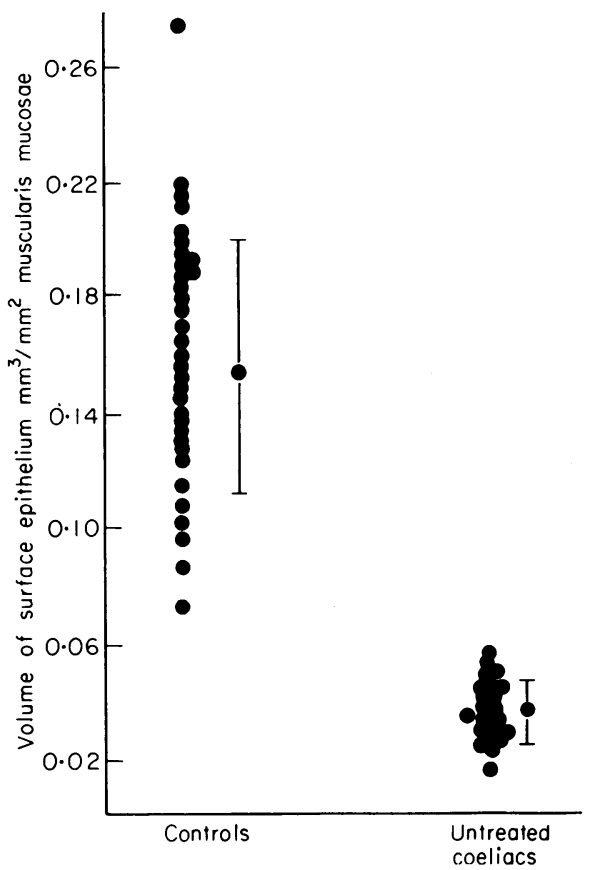

Fig. 6. Volumes of surface epithelial cells in controls and biopsies from untreated coeliacs. 


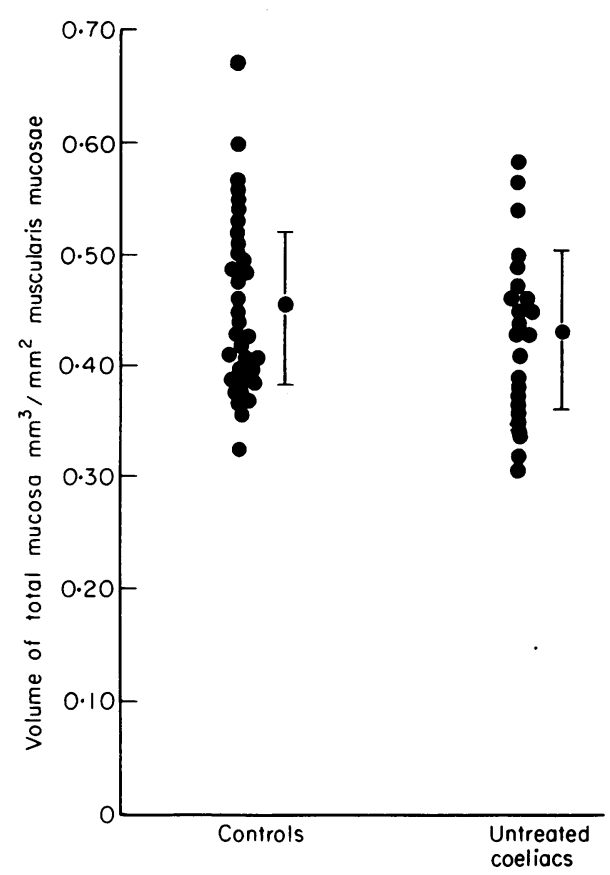

Fig. 7. The total mucosal volumes in controls and untreated coeliacs.

Results from the paired biopsies are shown in Fig. 4. A careful dietary history showed that all but three of the twenty-three children considered had kept rigidly to a gluten-free diet; first biopsies in these twenty patients had $c:$ lh ratios well within the control range. Of the first biopsies obtained from the three children in whom dietary lapses occurred, $c:$ lh ratios were well below the control range in two, and just at its lower end in the third. The reintroduction of dietary gluten produced a marked fall in $\mathrm{c}:$ lh ratios in thirteen of the twenty children with normal values on a gluten free diet; in eight of them $c:$ lh ratios were similar to those in untreated coeliacs and in the other five values fell in an intermediate range corresponding to so-called "partial villous atrophy'. In seven patients no fall in $\mathrm{c}: \mathrm{lh}$ ratio occurred when gluten was reintroduced.

\section{Method 2}

Numerous differences were recorded between controls and untreated coeliacs. Figures 5 and 6 show the results for both groups for surface area and surface epithelial cell volume. Total mucosal volumes in the two groups (Fig. 7) did not differ $(t=1 \cdot 19 ; P>0 \cdot 2)$.

\section{Discussion}

Morphometric methods used in histopathology (Dunnill, 1968; Weibel, 1963) involve the prediction of three dimensional volume and surface area $\stackrel{\varnothing}{\varrho}$ measurements of structures randomly distributed. within an organ or tissue, from area or perimeter $\vec{\Rightarrow}$ measurements of those structures seen in two dimen- + sional sections. However, the components of tissues? such as jejunal mucosa are not randomly distributed, $\frac{\bar{c}}{\bar{\rho}}$. so that meaningful comparisons between specimens? require that they be prepared in a similar fashion. $\unrhd$ In particular, a standard orientation of the tissue sections is chosen to best reveal their structure, $\vec{\circ}$ which in jejunal mucosa is at right angles to its ${ }_{-}^{-}$ surface. The level in the small intestine from which $\vec{\omega}$ a biopsy is taken is also important since variations in the mucosal appearances may occur at different siteso (Rubin and Dobbins, 1965).

Of the two methods of quantitative analysis? employed in the present study, that of Dunnill ando Whitehead (1972) provides a simple direct techniqueo needing a minimum of special equipment (an eye- $\searrow$ piece graticule specially made by Graticules Ltd) its advantages over other methods employing direct measurements of mucosal components is discussed by Dunnill and Whitehead (1972).

Computer card morphometry (Meinhard, 1974) iso a modification of point counting (Glasgolev, 1933)믐 but has a number of advantages over more traditionaltechniques. The data are already coded for compuerer analysis which forms an integral part of the techniqu: Furthermore, since the spatial arrangement of theo point counts are retained, the measured image can, in effect, be reconstructed within the computer. It iso in fact possible to produce pictorial as well as numeri cal printouts from the data suitable for inclusion in the patients' notes (Meinhard et al., 1975). Since्ठ the matrix is calibrated, volume and surface areas determinations can be derived in absolute terms.

The practical value of quantitative analysis of jejunal biopsy specimens, which compared with purely subjective interpretation is both tedious and time consuming, lies only partly in distinguishing and defining minor degrees of villous abnormality It also allows objective comparisons between specimens from different individuals or between seriaR biopsies from the same subject.

By determining surface-to-volume $(c: l h)$ ratio $\$$ in biopsies taken both before and after a gluten. challenge in twenty-three children previously treated empirically with a gluten free diet, the diagnosis of coeliac disease was confirmed in sixteen. In thirteen aD significant fall in $\mathrm{c}: \mathrm{lh}$ ratios occurred as a resultw of gluten ingestion confirming its deleterious effece on mucosal morphology in these patients; pres challenge values were well within the control rangep showing that in children with coeliac disease the mucosal lesion can heal completely with gluten withdrawal. In seven patients both pre- and post $\frac{\text { Oे }}{\bar{D}}$ challenge biopsies were normal. These children? 
almost certainly do not have coeliac disease, although a further biopsy after two years of gluten ingestion may be necessary to exclude a 'delayed' mucosal response to gluten (Walker-Smith, 1970, 1972).

A point of some interest regarding the morphogenesis of the mucosal lesion in coeliac disease is apparent from the computer card results. Although the surface epithelial volume is lower and the crypt epithelial volume greater in the biopsies from untreated coeliacs compared to the controls, the total mucosal volumes are the same (Fig. 8). Further, the lamina propria volume is only slightly greater in the coeliac biopsies despite an obvious increase in inflammatory cell infiltration. These results imply that the mucosal lesion involves a redistribution of tissue components, particularly surface and crypt epithelium, and not a change in the absolute amounts: that is, there is no true mucosal atrophy.

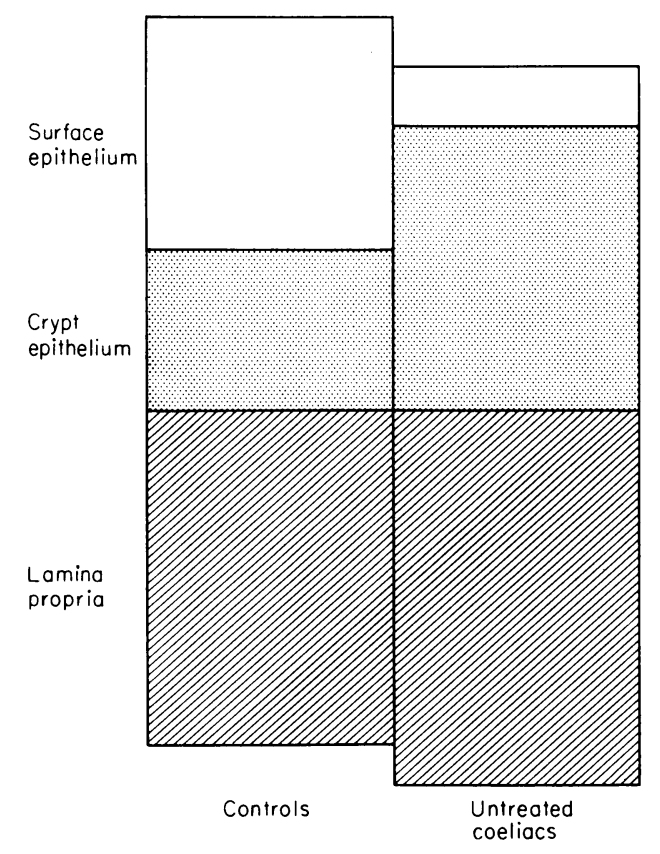

Fig. 8. Comparison of the mean volumes of total mucosa, epithelium and lamina propria in controls and untreated coeliacs. In the coeliac biopsies the fall in surface epithelial volume is associated with a rise in crypt epithelial volume.
Analysis of surface-to-volume (c: lh) ratios in the control biopsies relating them to the patients' ages showed that the lower $\mathrm{c}:$ lh ratios tended to occur in younger children (Fig. 3). This suggests that the complexity of the villous pattern increases at a varying rate during early childhood so that some young children have a relatively 'immature' mucosal morphology. This is supported by consideration of the dissecting microscope appearances of jejunal biopsies from young children which of ten have a 'ridged' pattern which might be considered pathological in an adult.

\section{References}

Anderson, C.M., Gracey, M. \& Burke, V. (1972) Coeliac disease. Some still controversial aspects. Archives of Disease in Childhood, 47, 292.

Chalkley, H.W., Cornfield, J. \& Park, H. (1949) A method for estimating volume-surface ratios. Science, 110, 295.

Chapman, B.L., Henry, K., Paice, F., Stewart, J.S. \& Coghill, N.F. (1973) A new technique for examining intestinal biopsies. Gut, 14, 903.

DunNill, M.S. \& Whitehead, R. (1972) A method for the quantitation of small intestinal biopsy specimens. Journal of Clinical Pathology, 25, 243.

DuNNiLl, M.S. (1968) Quantitative methods in histology. In: Recent Advances in Clinical Pathology; Series V (Ed. by S. C. Dykes) p. 40. Churchill, London.

Glasgolev, A.A. (1934) Quantitative analysis with the $\frac{0}{0} \overrightarrow{0}$ microscope by the 'point' method. Engineering and Mineralogy Journal, 135, 399.

MeInHARD, E.A. (1974) Histoquantitation using computer data cards. Journal of Microscopy, 101, 95.

MeinhaRd, E.A., WadBRoOK, D.G. \& Risdon, R.A. (1975) Computer card morphometry of jejunal biopsies in childhood coeliac disease. Journal of Clinical Pathology (in press).

Risdon, R.A. \& KeEling, J.W. (1974) Quantitation of the histological changes found in small intestinal biopsy specimens from children with suspected coeliac disease. Gut, $15,9$.

Rubin, C.E. \& Dobrins, W.O. (1965) Peroral biopsy of the small intestine: a review of its diagnostic usefulness. Gastroenterology, 49, 676.

Townley, R.R.W. \& Barnes, G.L. (1973) Intestinal biopsy in childhood. Archives of Disease in Childhood, 48, 480.

WADBROOK, D.G. \& MeINHARD, E.A. (1975) (in preparation).

WALKER-SMITH, J.A. (1970) Transient gluten intolerance. Archives of Disease in Childhood, 45, 523.

WALKER-SMITH, J.A. (1972) Transient gluten intolerance (correspondence). Archives of Disease in Childhood, 47, 155.

Weibel, E.R. (1963) Principles and methods for the morphometric study of the lung and other organs. Laboratory Investigation, 12, 131. 